\author{
SULPHUROUS ACID AS A DISINFECTANT \\ By Thomas W. Keates, Consulting Chemist to the Metro- \\ politan Board of Works, London.
}

From the remotest time burning sulphur has been en
ployed to fumigate and purify infected air, and to destroy fermentative and putrefactive action. There is no agent
more powerful in its effects than this. Unlike chlorine, not only acts as a disinfectant or destroyer of disease germs and of the results of putrefaction, but it is also a powerful
preservative agent, and, like carbolic acid, is a preventive
of chemical changes in dead organic matter of every kind. Although the value of su phurous acid is thoroughly unexists in the way of producing it in a form in which it can
be readily applied. The ordinary method of generating it be readily applied. The ordinary method of generating it by burning sulphur is cumbrous and very uncertain, owing
to the difficulty of keeping up the combustion; there are also all, and under the best circumstances it is inconvenient and but little under control. The evolution of the gas from its solution in water is scarcely more convenient, while it is ready, convenient, and easily controllable way of producing this valuable agent in use at present; and this is the more remarkable when it is considered what a ready and simple
means we really have at hand for this purpose. Most of the readers of The Lancet are no doubt familiar, at least theoretically, with the substance called bisulphide of carbon. This is a compound of one atom of carbon with
two atoms of sulphur $\left(\mathrm{CS}_{2}\right)$; it is a dense, mobile liquid, heavier than water, and intensely inflammable, burning in the air like spirit of wine. During combustion the constituents of the bisulphide combine with the oxygen of the air,
producing sulphurous and carbonic acid gases; but as 100 parts contain, by weight, as much as 84 parts of sulphur,
which will give, in burning, 168 parts of sulphurous acid, it will be seen that the volume of this gas from a given quanand is comparatively very "large. Suppose the above quantities to be in grains: as 100 cubic inches of sulphurous acid
weigh 68.5 grs., the $168 \mathrm{grs}$. will measure upwards of 245 cubic inches, or about one seventh of a cubic foot, which is
the volume of sulphurous acid obtainable from $100 \mathrm{grs}$. of bisulphide.

The bisulphide of carbon can be burned in a common
spirit lamp, and in that case the products are sulphurous acid spirit lamp, and in that case the products are sulphurous acid and carbonic acid only, in relative proportion to the atomic
composition of the bisulphide, as I have stated; but, by a ced in a given time can be regulated to any desired extent. It is a property of the bisulphide of carbon to dissolve in
fat oils and hydrocarbon liquids, such as petroleum; so, by mixing it with any one of these liquids and burning the mixture in a properly constructed oil or petroleum lamp, sulphur-
ous acid will be generated with the other usual products of ous acid will be generated with the other usual products of quantity of bisulphide present in the mixture of combustible liquids; any proportionate quantity of sulphurous acid can in this way be thrown into an atmosphere, and the action may be continued for any length of time.

As the sulphurous gas is generated pari passu during the
combustion of the bisulphide, it diffuses itself in the combustion of the bisulphide, it diffuses itself in the air w.th it. In a room containing about 1,300 cubic feet of air it was found that by burning 280 grs. of the bisulphide the atmosphere was so far charged with sulphurous acid that it seconds. In five minutes after the lamp was lighted litmus paper began to be reddened at some distance from it; in ten minutes the air had become very oppressive, and the litmus
paper was reddened in the extreme corners of the room; fifteen minutes the air was so charged with the gas that it could scarcely be breathed, and in twenty minutes it was phide were consumed in a simple single-wick lamp

Sulphurous acid generated in this manner can be applied wh has prevailed, it is only necessary to light the lamp and allow the gas to any desired extent, and become impregnated with guish it just like a common spirit lamp. In the simple form of apparatus which I suggest for this purpose, the lamp is 9 inches high, furnished with holes near the bottom for the admission of air, and others in the top for the emission of the placed, while the lamp is burning in almost about, and Receptacles for infected clothing, or the clothes or linen used in connection with disease, or carriages which have conveyed fever or other patients, can be thoroughly purified without
difficulty and with very little trouble. For the disinfection of ships, too, the lamp is particularly suitable, as it can be the least danger, and with the certainty of effecting its ob-

ject completely.
It must be observed that the bisulphide of carbon is ex-
tremely volatile, having its boiling point as low as $110^{\circ} \mathrm{F}$. tremely volatile, having its boiling point as low as $110^{\circ} \mathrm{F}$.
it is therefore necessary that the lamp in which it is burned it is therefore necessary that the lamp in which it is burned
should be furnished with a well fitting screw cap, to prevent the liquid from evaporating, and at the same time to keep it peculiar odor from escaping. This odor is often very nause-
ous, but the bisulphide is now manufactured by Messrs. C. Price \& Co., of Thames Street, London, England, so pure that it possesses very littie smell, and can be used withou
the least inconvenience. - The Lancet.

\section{NEW TEST PAPER}

M. Pierre Miquel.

The author finds that sulphocyanic acid produces upon spontaneously on exposure to the air, and more rapidly if a gentle heat be applied. Ammoniacal vapors destroy the
color immediately, and hydrochloric gas restores it. Thus a color immediately, and hydrochloric gas restores it. T
test paper is obtained far more sensitive than litmus.

WATERPROOFING WOOLLEN MATERIALS

The following method of renderingwoollen textures wat proof is recommended: Boil 125 grammes (about 42 ozs.) of
white soap in 12 litres (about $2 \frac{1}{2}$ gallons) of water, and separately dissolve 165 grammes (about 5: 5 ozs.) of alum lutions to $190^{\circ}$ Fahr.; then pass the woollen fabric once through the soap bath, and afterwards through the alum so-

\section{DECOLORATION OF INDIGO.}

M. E. Schaer.

IT is generally admitted that the decoloration of indigo by and, in fact, mere agitation in the air suffices to restore the blue color. But certain experiments seem to show that the
decoloration is produced by the formation of a colorless olecular compound. For indigo decolorized by hydro-sul hurous acid is regenerated, not only by the action of ai nd oxidizing agents, but also by decided reducing agents,
uch as sulphuretted hydrogen. Further, indigo bleached by the persulphide of hydrogen is restored by the action of sulphurous acid. These phenomena are explained by the sulphurous acid, and of sulphurous acid upon persulphide of hydrogen. We may, then, admit that indigo combines
with hydro-sulphurous acid and persulphide of hyhrogen, eration of the indigo by all agents capable of destroying
either hydro-sulphurous acid or persulphide of hydrogen. STILL'S GAS PURIFIER.

Fig. 1 is a longitudinal section of this purifier. A A is whole ratus, A remaining as before, light and adjust to zero. Now boxes which are placed around it, where it passes through the ends, C C, of the cylinder; and also in the upright bars,
D, D, D. E, E, E are a set of wooden rollers, affixed on the haft $B$; they are studded with strips of whalebone, or other
lexible material, throughout their whole length. A cross ExPERiMENT III-Arrange as in II. then extinguish the
ection of one of them is given in Fig. 2. The cylinder A,
sensitive flame and readjust to zero. Produce the respond
ing note, and the same movement of water will be observed.

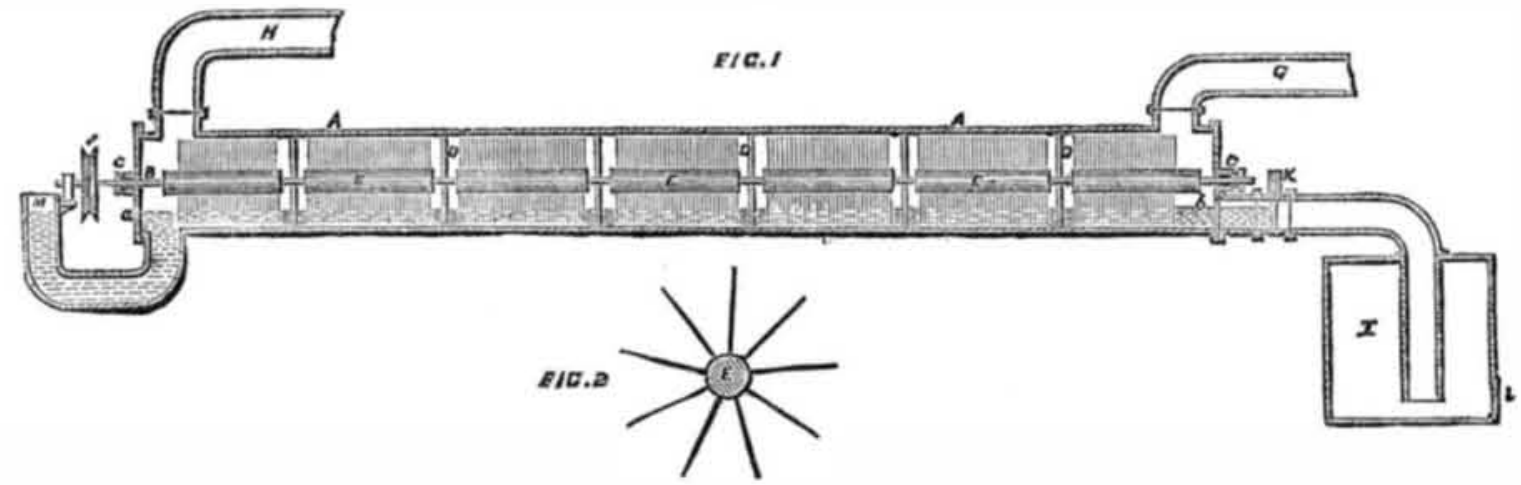

STILL'S GAS PURIFIER.

flime and water, or any other suitable liquid or solution; This shows that an issuing jet is affected in the same manne prime moving power passed over the pulley, F. The gas to by a sound, whether ignited or otherwise.
ExPERIMENT IV.-Fix the sensitive flame apparatus ad and after passing through the machine it escapes by the pipe, justed for note under a large jar open atboth ends. A larg $H$. When a fresh supply of water, or lime and water, is re- spongy platinum, $a, b$, and $c$, upon a piece of thin platinum quired, the previous or exhausted charge is allowed to flow wire so that the point of the quiescent flame just reaches $b$ lit can be subsequently removed through the door, L.
tively. Now extinguish the flame without turning off the

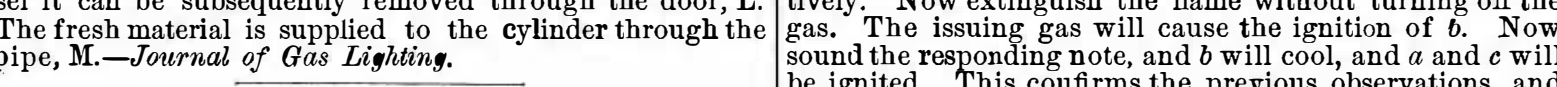

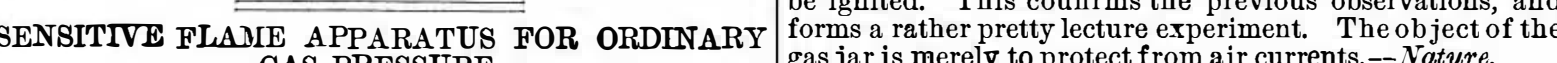
GAS PRESSURE.

A GLAss or metallic tube, about 5 inches long, and $\frac{5}{5}$ in diameter, is closed at one end with a perforated cork, through
this cork slides a piece of 1 inch tubing, about 6 inches long. One end of this is either drawn out to a jet, or closed in the

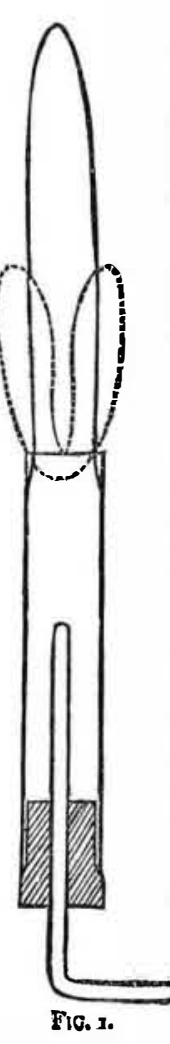
about $\frac{1}{16}$ inch, and the other end is connected to a gas supply. (Fig. 1.)
The outer tube is held in a suitable support, and the inner tube is pushed through the cork, till it nearly reaches the mouth of the outer
one, and a light then supplied. It now gives a long steady flame. ExPERIMENT I.-Lower the inner tube till the flame is on the point of roaring. It will now be found very sensitive to noise. Snapyards will cause it to contract fully ${ }^{\frac{4}{5}}$ or its
height. The most suitable flame for this is height. The most suitable flame for this is
about 6 inches high. ExPERIMENT II.-Adjust the gas to give a flame of about $4 \frac{1}{3}$ inches high, and gradually at which the flame becomes sensitive, not to noise, but note; and it will be found to re-
spond to a certain note by dividing into two spond to a certain note by dividing into two
portions, and while this note is produced it and therefore a glass whistle with paper slider with adjustment.

EXPERIMENT III.-Arrange two singing
tubes to give the responding note. The flame tubes to give the responding note. The flame
divides. Now make one tube a little sharper divides. Now make one tube a little sharper
than the other, so as to beat slowly The alæ of the flame alternately recede and coalesce. ExPERIMENT IV.-Using the whistle; blow
it so hard as to produce higher octaves of the responding note. The flame will be unaffected as though in perfect silence.

to great variation, and also the size of the flame. For lecture work, a flame $1 \frac{1}{2}$ or 2 feet would be more suitable, though less sensitive, and neither It will act effectively with any pressure of gas, from $\frac{1}{10}$ inch
(of water) upwards, and the sliding jet makes it equally

ESCAPE OF GAS FROM CONTRACTED OPENINGS.

Glass tubes of about 1 inch bore are joined, as shown in Fig. 2. At D the tube is slightly bent so as to retain a little
drop of water. The gas enters at $\mathbf{C}$, and then divides into wo channels, one towards B, the other towards A. If one
of the exits be contracted, say $B$ then the water moves towurds A. Certain precautions have to be observed, the condit
here.
ExPERIMENT I.-Connect to each, A and B, a tapering jet,
nd C with the gas supply. Get the water stationary. Now This is rather a remarkable result, seeing that the gas is must enlarge the aperture. Now light $\mathbf{A}$, and the water
molle, EXPERIMENT II.-Connect B with a sensitive flame appa-

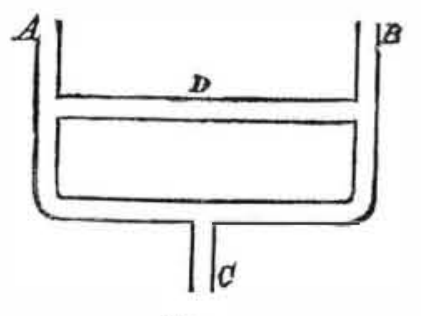

ound the responding note and the water moves towards A, the. Now adjust the sensitive flame for noise, and rapidly $p$ the fingers or stamp the foot, and the water will still ove towards A.

forms a rather pretty lecture experiment. The is merely to protect from air currents.--Nature.
gas jar

THE CHEMISTRY OF COAL

A Codrse of six lectures to workingmen on the above
subject was lately given by Dr. Frankland, F.R.S., in the Chemical Lecture Theatre, South Kensington, in connection there is no rently uninteresting it may be, which will not prove itself worthy of our attention if we examine it carefully, though
t be merely a piece of sandstone, or even a brickbat. All of them have wonderfulhistories to tell us if we only apply to them those powers of observation and experiment which
re always at hand; but no substance in nature, perhaps, has are always at hand; but no substance in nature, perhaps, has
such a wonderful history and extraordinary properties as pon it. Simplnute observation than is ordirarily bestowed n opaque, brittle, hardish black substance; thrown on the fire swells, gives off dense smoke, glows, and eventually
burns. Coal is found embedded almost exclusively in cerburns. Coal is found embedded almost exclusively in cerarboniferous system, in which these coal measures occur, diagram. The coal is found of the coal measures in very thin seams compared with those rocks. The amount of this coal is, after all, very enor-
mous, even the quantity we have in this country, and we ave a very large share of the total coal worked in Europe mount of coal raised per annum order according to the highest, the following countries stand thus: British Isles, Germany, United States, Belgium, France, Russia, Austria, Spain. The following statements as to the amount raised yearly in the British Isles will, perhaps, be striking to some. If we were to dig a hole through the centre of the earth
hat hole would be 8,000 miles long; now, if the coal raised in one year in Great Britain were made into a bar 1 yard quare, each yard of the bar weighing about 1 ton, the porbout one seven within the hole mentinned would represent cumference of the earth is about 24,000 miles, and if the coal raised in Great Britain in a year were made into a band 1 yard thick and 7 yards wide (each yard weighing, therefore,
about 7 tons), that band would go all round the earth and leave about 3,000,000 yards to spare. The coal raised in earth and the moon with a bar 1 yard square. The quantity raised in Great Britain yearly is between 100,000,000 and $107,000,000$ tons. The quantity we possess is, after all, limted, and if we go on digging coal in this way it will before any long become a pressing problem how we are to prevent
any waste of this valuable material. From the best sources than $4,000 \mathrm{ft}$, only mate, we have still to get, at less depths than 4,000 ft., only
about $83,000,000,000$ tons. light, say $\mathrm{B}$, the water will move towards A, showing that coal. To ascertain this history and these properties it will 